medRxiv preprint doi: https://doi.org/10.1101/2020.04.07.20057166; this version posted April 10, 2020. The copyright holder for this preprint

(which was not certified by peer review) is the author/funder, who has granted medRxiv a license to display the preprint in perpetuity. It is made available under a CC-BY-NC 4.0 International license.

Structural correlates of apathy and negative symptoms

\title{
Orbitofrontal-striatal structural alterations linked to negative symptoms at different stages of the schizophrenia spectrum
}

\author{
Matthias Kirschner, ${ }^{1,2}$, André Schmidt ${ }^{3}$, Benazir Hodzic-Santor ${ }^{1}$, Achim Burrer ${ }^{2}$, Andrei \\ Manoliu ${ }^{2,4,5}$, Yashar Zeighami ${ }^{1}$, Yvonne Yau ${ }^{1}$, Nooshin Abbasi ${ }^{1}$, Anke Maatz ${ }^{2}$, Benedikt \\ Habermeyer $^{6}$, Aslan Abivardi ${ }^{2}$, Mihai Avram ${ }^{7}$, Felix Brandl ${ }^{8}$, Christian Sorg ${ }^{7,8}$, Philipp \\ Homan $^{2,9,11}$, Anita Riecher-Rössler ${ }^{12}$, Stefan Borgwardt ${ }^{3}$, Erich Seifritz ${ }^{2}$, Alain Dagher ${ }^{1 *}$ and \\ Stefan Kaiser ${ }^{13 *}$
}

\section{Affiliations}

${ }^{1}$ Montreal Neurological Institute, McGill University, Montreal, Quebec, Canada

${ }^{2}$ Department of Psychiatry, Psychotherapy and Psychosomatics, Psychiatric Hospital, University of Zurich, Switzerland

${ }^{3}$ Department of Psychiatry (UPK), University of Basel, Basel, Switzerland

${ }^{4}$ Wellcome Centre for Human Neuroimaging, University College London, London, United Kingdom

${ }^{5}$ Max Planck University College London Centre for Computational Psychiatry and Ageing Research, London, United

Kingdom

${ }^{6}$ Psychiatric Services Aargau, Brugg, Switzerland

${ }^{7}$ Department of Neuroradiology and TUM-NIC Neuroimaging Center, Klinikum rechts der Isar, Technische Universität München, Munich, 81675, Germany

${ }^{8}$ Department of Psychiatry and TUM-NIC Neuroimaging Center, Klinikum rechts der Isar, Technische Universität München, Munich, 81675, Germany

${ }^{9}$ Center for Psychiatric Neuroscience, Feinstein Institute for Medical Research, Manhasset, NY

${ }^{10}$ Division of Psychiatry Research, Zucker Hillside Hospital, Northwell Health, New York, NY

${ }^{11}$ Department of Psychiatry, Donald and Barbara Zucker School of Medicine at Northwell/Hofstra, Hempstead, NY

${ }^{12}$ Medical Faculty, University of Basel, Switzerland

${ }^{13}$ Division of Adult Psychiatry, Department of Psychiatry, Geneva University Hospitals, Switzerland

*equal contribution

Corresponding Author: Matthias Kirschner, McConnell Brain Imaging Centre, Montréal Neurological Institute, McGill University, 3801 Rue University, Montréal QC, H3A 2B4 Canada, email: matthias.kirschner@mail.mcgill.ca, Tel: (514) 3981726. 
medRxiv preprint doi: https://doi.org/10.1101/2020.04.07.20057166; this version posted April 10, 2020. The copyright holder for this preprint (which was not certified by peer review) is the author/funder, who has granted medRxiv a license to display the preprint in perpetuity. It is made available under a CC-BY-NC 4.0 International license .

Structural correlates of apathy and negative symptoms

\begin{abstract}
Among the most debilitating manifestations of schizophrenia are negative symptoms such as anhedonia and apathy. Imaging studies have linked these symptoms to morphometric abnormalities in two brain regions implicated in reward and motivation: the orbitofrontal cortex (OFC) and ventral striatum. Negative symptoms generally are associated with reduced OFC thickness, while apathy specifically maps to reduced striatal volume. However, it remains unclear whether these tissue losses are a consequence of chronic illness and its treatment, or an underlying phenotypic trait. Here we use multicentre MRI data to investigate orbitofrontalstriatal abnormalities across the schizophrenia-spectrum from healthy populations with schizotypy, to unmedicated and medicated first-episode psychosis patients, and patients with chronic schizophrenia. Striatal volumes and OFC thickness were estimated from T1-weighted images acquired in all three diagnostic groups and controls from four sites $(n=337)$. Results were first established in one test cohort ("Zurich sample") and replicated in three independent samples. There was a correlation between apathy and striatal volume only in healthy individuals with schizotypy; however, medicated patients exhibited larger striatal volumes, which appears to be a consequence of antipsychotic medications. The association between reduced OFC thickness and negative symptoms generally also appeared to vary along the disease course, being significant only in first-episode psychosis patients. In schizotypy there was increased OFC relative to controls. Our findings suggest that negative symptoms associate with a temporal continuum of orbitofrontal-striatal abnormalities that may predate the occurrence of schizophrenia. Thicker OFC in schizotypy may represent either compensatory or pathological mechanisms prior to disease-onset.
\end{abstract}


medRxiv preprint doi: https://doi.org/10.1101/2020.04.07.20057166; this version posted April 10, 2020. The copyright holder for this preprint (which was not certified by peer review) is the author/funder, who has granted medRxiv a license to display the preprint in perpetuity. It is made available under a CC-BY-NC 4.0 International license .

Structural correlates of apathy and negative symptoms

\section{Introduction}

Negative symptoms of schizophrenia are a multifaceted clinical construct occurring in all stages of the disorder. ${ }^{1}$ Consistent with a continuum model of psychosis, subclinical manifestations of negative symptoms can also be observed in the general population, especially in individuals with higher psychosis-proneness such as schizotypy. ${ }^{2-4}$ Negative symptoms comprise a diverse set of symptoms including avolition, anhedonia, asociality, alogia and blunted affect. ${ }^{5,6}$ In particular motivational and hedonic deficits (herein referred to as apathy) are associated with diminished quality of life, higher disease burden and in general poor long-term prognosis. ${ }^{7-11}$

Converging lines of research emphasize that functional and structural abnormalities of the cortico-striatal reward circuit are involved in the development of negative symptoms in schizophrenia. ${ }^{12-14}$ One of the most consistent findings from functional magnetic resonance imaging (fMRI) in schizophrenia is the association between negative symptoms and blunted ventral striatum (VS) activation. ${ }^{15,16}$ More specifically, apathy has been related to blunted striatal activation during: reward anticipation ${ }^{17-22}$, reward feedback processing ${ }^{23}$ and prediction error coding. ${ }^{24,25}$ These associations extend across a continuum from the general population to individuals in at-risk stages and early psychosis ${ }^{26,27}$, although negative ${ }^{28,29}$ and contradictory findings have been reported..$^{30}$ In addition, prefrontal hypoactivation has been linked to negative symptoms in patients with schizophrenia (SZ). ${ }^{20,23-25,31,32}$

Consistent with this accumulating evidence of abnormal fronto-striatal circuit function, a picture of neuroanatomical changes related to negative symptoms in schizophrenia has started to emerge. 12,33,34 Two recent studies found that reduced VS volume is associated with apathy, ${ }^{35,36}$ while a recent meta-analysis found consistent evidence for an association between reduced orbitofrontal cortical thickness and global negative symptoms. ${ }^{37}$ Together, these findings suggest that structural correlates of negative symptoms in schizophrenia map onto a similar circumscribed set of brain regions implicated in motivation and reward. However, it is unclear whether this also holds across non-clinical and early stages of the schizophreniaspectrum. Only few studies have directly investigated the association between structural brain abnormalities and negative symptoms in other groups of the schizophrenia-spectrum such as non-clinical populations with psychotic-like experiences (e.g. schizotypy ${ }^{38,39}$, individuals in at-risk stages ${ }^{40}$, first-episode psychosis patients (FEP) ${ }^{41,42}$ or untreated schizophrenia. ${ }^{43}$ In this regard, transdiagnostic approaches may help to shed light on shared or divergent structural signatures of negative symptoms across the entire disease spectrum. Specifically, including non-clinical populations with high schizotypal personality traits (SPT) and only minimally treated first-episode psychosis patients offers the unique opportunity to study brain-behaviour relationships in the absence of structural changes related to long-term antipsychotic treatment and chronic psychosis. ${ }^{44-46}$ Thus, transdiagnostic approaches may inform whether tissue losses are a consequence of chronic illness and its treatment, or an underlying phenotypic trait such as negative symptoms.

Here, we used multicentre MRI data from four research centers to investigate orbitofrontalstriatal structural correlates of apathy and global negative symptoms across a continuum of nonclinical, unmedicated individuals with SPT, unmedicated and medicated patients with FEP, and patients with SZ. Based on previous findings in $\mathrm{SZ}^{35-37}$, we hypothesized that reduced striatal 
medRxiv preprint doi: https://doi.org/10.1101/2020.04.07.20057166; this version posted April 10, 2020. The copyright holder for this preprint (which was not certified by peer review) is the author/funder, who has granted medRxiv a license to display the preprint in perpetuity. It is made available under a CC-BY-NC 4.0 International license .

Structural correlates of apathy and negative symptoms

volumes are correlated with apathy, while reduced OFC thickness is correlated with global negative symptom severity within each subgroup of the schizophrenia-spectrum. We first performed the analysis in a dataset from Zurich that includes all three subgroups (SPT,FEP,SZ). We then attempted to confirm significant findings in three additional independent datasets including one sample of individuals with SPT (Montreal dataset), one sample of patients with FEP (Basel dataset), and one sample of patients with SZ (Munich dataset). Finally, to identify patterns of orbitofrontal-striatal structural abnormalities related to different stages of the schizophrenia-spectrum, we combined all four datasets $(n=337)$ and compared orbitofrontalstriatal structural measures between subgroups of the schizophrenia-spectrum and healthy controls (HC).

\section{Methods}

\section{Participants \\ Study I (Zurich dataset)}

The current sample of 129 individuals (28HC, 27SPT, 26FEP, 48SZ) was derived from previously published fMRI studies investigating the association between reward system dysfunction and negative symptoms. ${ }^{17,19,30}$ All SZ patients and FEP patients were recruited from outpatient and inpatient units at the Psychiatric Hospital of the University of Zurich. Healthy individuals were recruited using an online survey of the Schizotypal Personality Questionnaire (SPQ) ${ }^{47} 956$ participants completed the questionnaire (mean=16.66, $\mathrm{SD}=11.34$ ). Individuals with the highest SPQ total scores $(>10 \%)$ were invited to participate in the MRI study.

\section{Study II (Montreal dataset)}

The confirmation sample for the schizotypy group was derived from a neuroimaging study by Soliman et al. ${ }^{48}$ investigating high positive SPT based on the Perceptual Aberration Scale $(\text { PerAb })^{49}$ and high negative SPT based on the Physical Anhedonia Scale (PhysAn) $)^{50}$. Individuals were recruited from undergraduate classes at McGill University and SPT groups were recruited by virtue of scoring $>1.95$ S.D. above the mean of their sex on either scale but not on both. The total sample comprises 40 healthy individuals (13 high positive SPT, 12 high negative SPT, 15 low SPT). ${ }^{48}$

\section{Study III (Basel dataset)}

The confirmation sample for the FEP group was derived from previous neuroimaging studies. ${ }^{51-}$ 53 The initial sample comprises in total 119 individuals (74FEP, 45HC). 14FEP had to be excluded from the correlation analysis due to missing negative symptoms scores.

\section{Study IV (Munich dataset)}

The confirmation sample for the SZ group was derived from a study by Avram and colleagues $(n=49) .{ }^{54}$ Twenty-six chronic SZ patients $(>=$ two psychotic episodes and currently in symptomatic remission of positive symptoms according to ${ }^{55}$ ) and $23 \mathrm{HC}$ were included. 
medRxiv preprint doi: https://doi.org/10.1101/2020.04.07.20057166; this version posted April 10, 2020. The copyright holder for this preprint (which was not certified by peer review) is the author/funder, who has granted medRxiv a license to display the preprint in perpetuity. It is made available under a CC-BY-NC 4.0 International license .

Structural correlates of apathy and negative symptoms

All four studies were approved by the local ethics committees, and all participants gave written informed consent after receiving a complete description of the study. For more details on inclusion and exclusion criteria of all datasets please see supplementary methods.

\section{Image acquisition and processing}

Image acquisition parameters are described in the supplementary methods. We processed T1weighted structural brain scans from all four datasets using FreeSurfer Version 6.0. ${ }^{56}$ Based on our a priori hypothesis, we followed a region-of-interest (ROI) approach and extracted striatal volumes for the left and right nucleus accumbens (NAcc), caudate and putamen ${ }^{57}$, as well as left and right medial orbitofrontal cortex (MOFC) and lateral orbitofrontal cortex (LOFC) thickness values based on the Desikan-Killiany atlas. ${ }^{58}$ In total, our ROI analysis consists of 10 ROIs ( 5 for each hemisphere). Quality control followed the standardized ENIGMA protocols for subcortical and cortical analysis (http://enigma.ini.usc.edu/protocols/imaging-protocols), which have been used in several previous studies (see supplementary methods). ${ }^{37,44,59-61}$

\section{Assessment of Negative Symptoms}

\section{Study I (Zurich dataset)}

The Brief Negative Symptoms Scale (BNSS) was used to assess the severity of negative symptoms in all individuals of the schizophrenia-spectrum (SPT,FEP,SZ) ${ }^{62-64}$ The BNSS total score combined all items and was used to measure global severity of negative symptoms. The BNSS apathy dimension (avolition, asociality, anhedonia) and BNSS diminished expression (blunted affect, alogia) was calculated following the 2-factor solution proposed by Mucci and colleagues. ${ }^{65}$ In this context BNSS apathy reflects reduced motivation and engagement in goaldirected behaviour and diminished experience of pleasure, while BNSS diminished expression reflects decrease in facial and vocal expression, or body gestures, and reduced quantity of speech and spontaneous elaboration. ${ }^{5,66}$ Of note, recent studies have suggested that a more finegrained differentiation of negative symptoms into five factors may provide a better fit to the psychometric data. ${ }^{67-69}$ Here, we used the consensual two-factor/domain model, for the following reasons. First, psychometric advantages of a five-factor model across all groups of the schizophrenia-spectrum remain to be determined. ${ }^{67}$ Second, our a priori hypothesis is based on studies that have successfully applied two-factor/domain models to identify specific brain correlates of apathy. ${ }^{17,19,36,70}$ Third, a more granular differentiation into avolition, asociality, and anhedonia would increase the risk of type I error.

\section{Study II (Montreal dataset)}

The dataset from Soliman and colleagues ${ }^{48}$ did not include a clinical-rating of negative symptoms but used the 61 items from the PhysAn scale ${ }^{50}$ to assess negative schizotypy. PhysAn total scores were used to measure self-reported deficits in motivation and pleasure.

\section{Study III (Basel dataset)}

Negative symptoms in FEP were measured with the 24-item version of the Scale for the Assessment of Negative Symptoms (SANS). ${ }^{71}$ The Global SANS (summary) score consisted of all four global items $(7,12,16,21)$. Following the approach from Strauss and colleagues ${ }^{10}$, the SANS Global avolition-apathy subscore (items:16,21) was defined to assess deficits in 
medRxiv preprint doi: https://doi.org/10.1101/2020.04.07.20057166; this version posted April 10, 2020. The copyright holder for this preprint (which was not certified by peer review) is the author/funder, who has granted medRxiv a license to display the preprint in perpetuity. It is made available under a CC-BY-NC 4.0 International license .

Structural correlates of apathy and negative symptoms

motivation and pleasure and the SANS Global affect-alogia subscore (items:7,12) was defined to assess diminished expression.

\section{Study IV (Munich dataset)}

The Positive and Negative Symptom Scale (PANSS) was used and global negative symptoms were defined according to the Marder negative symptom factor. ${ }^{72}$ To assess severity of apathy, we calculated the PANSS amotivation factor described previously. ${ }^{11}$

\section{Statistical analysis}

\section{Association with negative symptoms}

For each subgroup (SPT,FEP,SZ) of the schizophrenia-spectrum, separate Spearman rank correlations were used to investigate an association of apathy and global/total negative symptoms with striatal volumes and OFC thickness (psych package 1.8.12 $2^{73}$, R version 3.6.1 ${ }^{74}$ ). Based on previous findings ${ }^{35-37}$, an association between apathy and reduced striatal volume and an association between global negative symptoms and reduced OFC thickness were hypothesized. Covariates were included following the statistical approach of recent studies from the ENIGMA consortium. ${ }^{37,44,59,61}$ For subcortical analysis the model included age, sex and intracranial volume (ICV) as covariates. For cortical analyses, the model included age and sex as covariates. In order to confirm significant findings from study I, the same correlation analyses were repeated for healthy individuals with SPT using the dataset from study II, for FEP patients using the dataset from study III and for patients with SZ using the dataset from study IV. Multiple comparison of the primary analysis in study I was adjusted for the number of total tests ( $\mathrm{n}=30,10$ tests per each group) using false discovery rate $\mathrm{p}<0.05$ (BenjaminiHochberg procedure). ${ }^{75}$ Subsequent confirmation analyses in study II, study III and study IV were only performed in those ROIs in which significant association with either apathy and subcortical volumes or global negative symptoms and OFC thickness had been observed. Confirmation analyses are reported with an uncorrected threshold of $\mathrm{p}<0.05$.

\section{Group comparison}

Group comparisons with data from all sites ( $\mathrm{n}=337)$ were performed using multivariate analysis of covariance (MANCOVA) and univariate analysis of covariance (ANCOVA) for subsequent post-hoc analyses (jmv package ${ }^{76}, \mathrm{R}$ version 3.6.1 ${ }^{74}$ ). Following recent reports ${ }^{37,44,59,61}$, two separate models were defined: (1) for striatal volumes including accumbens, caudate and putamen volume as dependent variable, group as fixed factor and age, sex, ICV, and acquisition site as covariates; (2) for cortical thickness including left and right MOFC, LOFC as dependent variable, group as fixed factor and age, sex, and site as covariates. Post-hoc pairwise comparisons were controlled for multiple comparison using the Bonferroni correction. 
medRxiv preprint doi: https://doi.org/10.1101/2020.04.07.20057166; this version posted April 10, 2020. The copyright holder for this preprint (which was not certified by peer review) is the author/funder, who has granted medRxiv a license to display the preprint in perpetuity. It is made available under a CC-BY-NC 4.0 International license .

Structural correlates of apathy and negative symptoms

\section{Results}

\section{Demographics and clinical data}

Demographic and clinical data from all four datasets can be found in Table 1 .

\section{Association between apathy and reduced striatal volume Individuals with SPT}

In healthy individuals with SPT $(n=27)$, BNSS apathy scores were negatively associated with volume of the right NAcc ( $\mathrm{rs}=-.54$, FDR-adjusted $\mathrm{p}=.02$ ), and bilateral putamen (right: $\mathrm{rs}=-.58$, FDR-adjusted $\mathrm{p}=.01$ : left: $\mathrm{rs}=-.63$, FDR-adjusted $\mathrm{p}=.009$ ) accounting for age, sex and intracranial volume (Fig. 1, Table 2A). Using Steiger's test ${ }^{77}$, we could show that the associations between BNSS apathy with right NAcc and right putamen volume were significantly stronger than the association between BNSS apathy and the right caudate volume (Table S1). These findings indicate regional specificity of the relationship with apathy with respect to the right NAcc and right putamen volume.

No association of subcortical volumes with BNSS diminished expression or potential confounding variables such as subclinical depressive symptoms, subclinical positive symptoms and cognition were observed (Table S1). Using Steiger's test ${ }^{77}$, we found that the associations between BNSS apathy and right NAcc as well as bilateral putamen were significantly stronger than the association between BNSS diminished expression and the respective striatal volumes (supplementary results). In other words, reduced striatal volumes are specifically associated with apathy and not related to other negative symptoms.

In a next step, we aimed to confirm these findings in an independent sample (Montreal dataset) with varying levels of schizotypy. We found a significant negative association of PhysAn with right and left NAcc and right putamen in the subgroup with positive schizotypy $(n=13)$ and moderate severity of PhysAn (Raccumb: $r s=-.84, p=.002$; Laccumb: $r s=-.68, p=.03$; Rput: $r s=-$ $.78, \mathrm{p}=.008)$. Pointing in the same direction, individuals with high negative schizotypy $(\mathrm{n}=12)$ showed a non-significant correlation between PhysAn right accumbens volume and right putamen volume (Raccumb: $r s=-.495, \mathrm{p}=.175$, Rput: $r s=-.318, \mathrm{p}=.4$ ) (Table S1). In addition, the subgroup with low positive and negative schizotypy $(n=15)$ showed a significant negative correlation between PhysAn and right and left NAcc volumes (Raccumb: $r s=-.51, p=.088$; Laccumb: rs=-.62, p=.03) (Table S1, Fig S2).

\section{Patients with FEP and SZ}

In FEP, BNSS apathy scores were not significantly associated with the volumes of striatal subregions (Table 2A). Similarly, BNSS apathy did not significantly correlate with striatal volumes in patients with SZ (Table 2A).

Taken together, reduced striatal volume was associated with different measures of motivation and pleasure (BNSS apathy, PhysAn) in two independent datasets of unmedicated healthy individuals with SPT. This relationship was not detectable in FEP and SZ. 
medRxiv preprint doi: https://doi.org/10.1101/2020.04.07.20057166; this version posted April 10, 2020. The copyright holder for this preprint (which was not certified by peer review) is the author/funder, who has granted medRxiv a license to display the preprint in perpetuity. It is made available under a CC-BY-NC 4.0 International license.

Structural correlates of apathy and negative symptoms
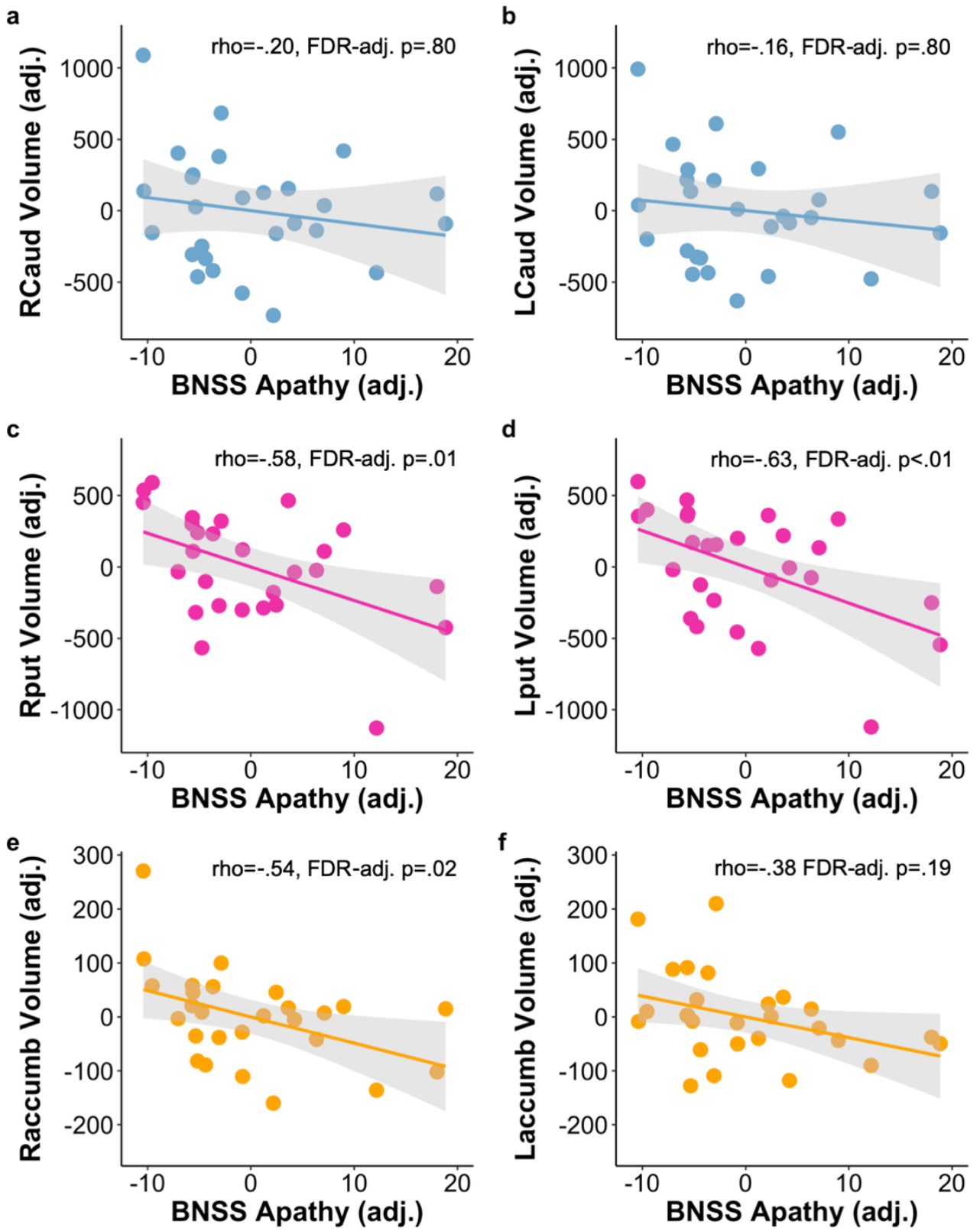

g

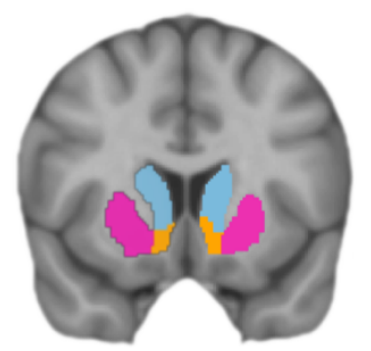

Figure 1. Association between striatal volumes and subclinical apathy in schizotypy

Zurich SPT Sample ( $\mathrm{n}=27)$. For visualisation purpose, partial correlations between subcortical volume and BNSS Apathy are shown as Pearson correlation coefficients and two-tailed significance tests using R. Regressions were adjusted for age, sex, intracranial volume. Error shadings correspond to standard errors. adj., adjusted. Significant associations are observed in (c) right putamen ( $\mathrm{rs}=-.58$, FDR-adjusted $\mathrm{p}=.01$ ), (d) left putamen ( $\mathrm{rs}=-.63$, FDR-adjusted $\mathrm{p}=.009$ ) and (e) right NAcc ( $\mathrm{rs}=-.54$, FDR-adjusted $\mathrm{p}=.02$ ). In contrast, correlation analysis between BNSS apathy and (a) right caudate volume ( $\mathrm{rs}=-.20$, FDRadjusted $\mathrm{p}=.80$ ), (b) left caudate volume ( $\mathrm{rs}=-.16$, FDR-adjusted $\mathrm{p}=.80$ ), and (f) left NAcc ( $\mathrm{rs}=-.38$, FDR-adjusted $\mathrm{p}=.19)$ were not significant. $(\mathrm{g})$ visualization of the six striatal volumes, skyblue $=$ caudate, pink $=$ putamen, orange $=$ nucleus accumbens. 
medRxiv preprint doi: https://doi.org/10.1101/2020.04.07.20057166; this version posted April 10, 2020. The copyright holder for this preprint (which was not certified by peer review) is the author/funder, who has granted medRxiv a license to display the preprint in perpetuity. It is made available under a CC-BY-NC 4.0 International license .

Structural correlates of apathy and negative symptoms

\section{Association between global negative symptoms and OFC thickness Individuals with SPT}

In healthy individuals with SPT, global negative symptoms (BNSS Total) were not correlated with reduced OFC thickness. In contrast, greater right MOFC thickness was positively correlated with BNSS total scores ( $\mathrm{rs}=0.462, \mathrm{p}=0.02$ ), but this effect did not remain significant after correction for multiple comparisons (Table 2A).

\section{Patients with FEP and SZ}

In patients with FEP, global negative symptoms (BNSS Total) were negatively associated with cortical thickness of right and left LOFC (right: $r s=-.624$, FDR-adjusted $\mathrm{p}=.02$, left: $\mathrm{rs}=-.613$, FDR-adjusted $p=.02$, Fig. 2, Table 2A). Pointing in the same direction, thickness of right and left MOFC showed trend-level negative correlations with BNSS total scores (Table 2A). Regarding potential confounding variables, OFC thickness was not associated with current medication dose (chlorpromazine equivalents), depressive symptoms, positive symptoms, and cognition (Table S4). Additionally, association between LOFC and global negative symptoms did not change when adding current medication dose as covariate in the model (right: $r s=-.619$, $\mathrm{p}=.002$; left: $\mathrm{rs}=-.608, \mathrm{p}=.002$ ).

In a next step, we aimed to confirm these findings in an independent FEP sample ( $n=60$, Basel). We found a significant negative association of global negative symptoms (SANS global score) with left LOFC thickness (right: $r s=-.13, p=.329$, left: $r s=-.319, p=.015$ ). We addressed the relationship between OFC thickness and potential confounding variables and observed a significant correlation between depressive symptoms (BPRS depressive subscore) and left LOFC thickness ( $\mathrm{rs}=-.27, \mathrm{p}=.02)$ as well as depressive symptoms and global negative symptoms ( $r s=.51, p<.0001)$. Furthermore, when including depressive symptoms as additional covariate in the model the association between global negative symptoms and left LOFC was no longer significant ( $\mathrm{rs}=-.169, \mathrm{p}=.21$ ). No association was observed with medication (chlorpromazine equivalents) or positive symptoms (Table S4) and the relationship between left LOFC and global negative symptoms did not change when adding current medication dose as covariate in the model (left: $r s=-.338, p=.001)$.

Patients with SZ showed a non-significant negative correlation between right MOFC thickness and BNSS total scores (Table 2A).

In Sum, reduced LOFC thickness was associated with total negative symptoms in two independent FEP datasets. Conversely in SPT, MOFC thickness was positively correlated with subclinical negative symptoms. 
medRxiv preprint doi: https://doi.org/10.1101/2020.04.07.20057166; this version posted April 10, 2020. The copyright holder for this preprint (which was not certified by peer review) is the author/funder, who has granted medRxiv a license to display the preprint in perpetuity. It is made available under a CC-BY-NC 4.0 International license .

Structural correlates of apathy and negative symptoms
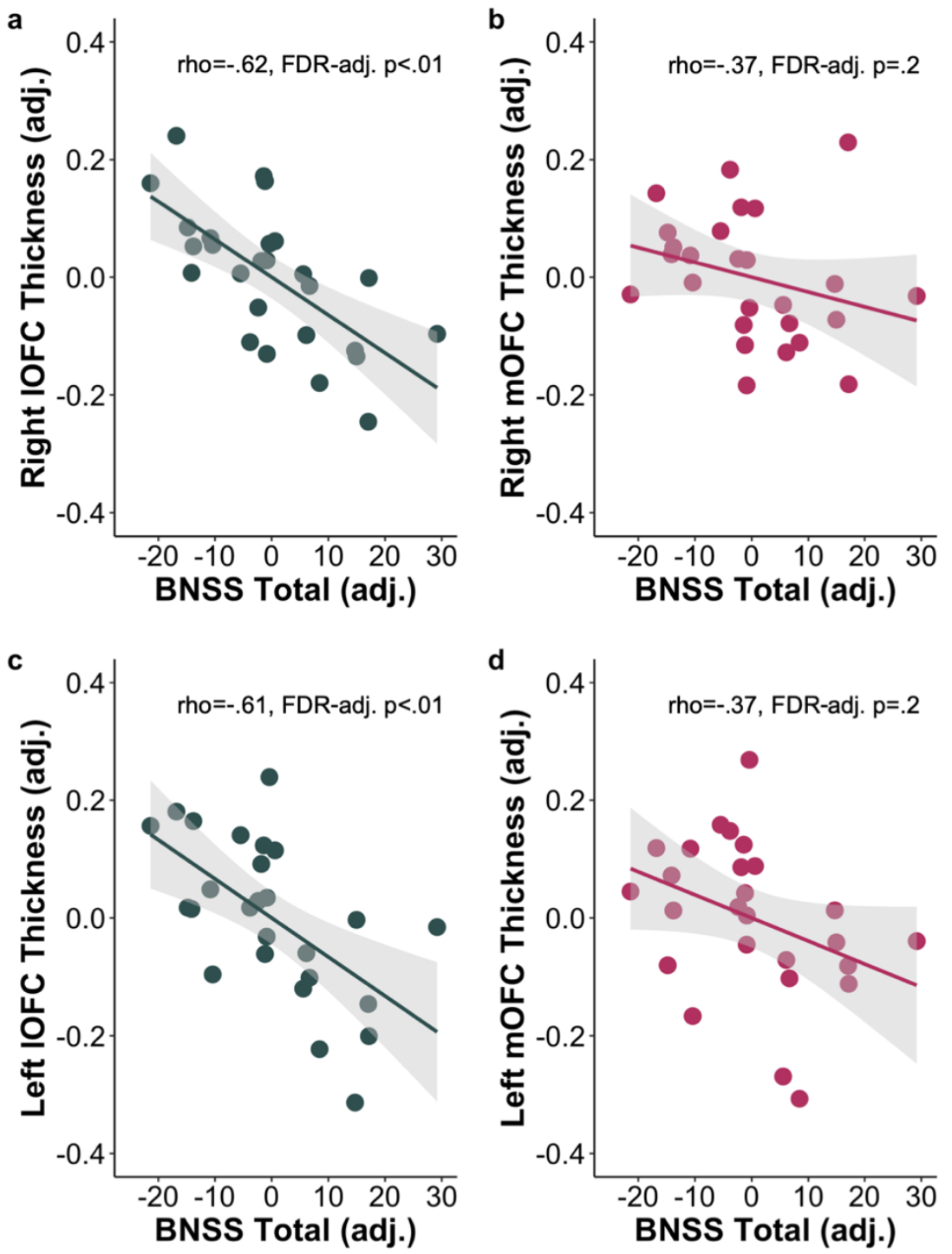

e

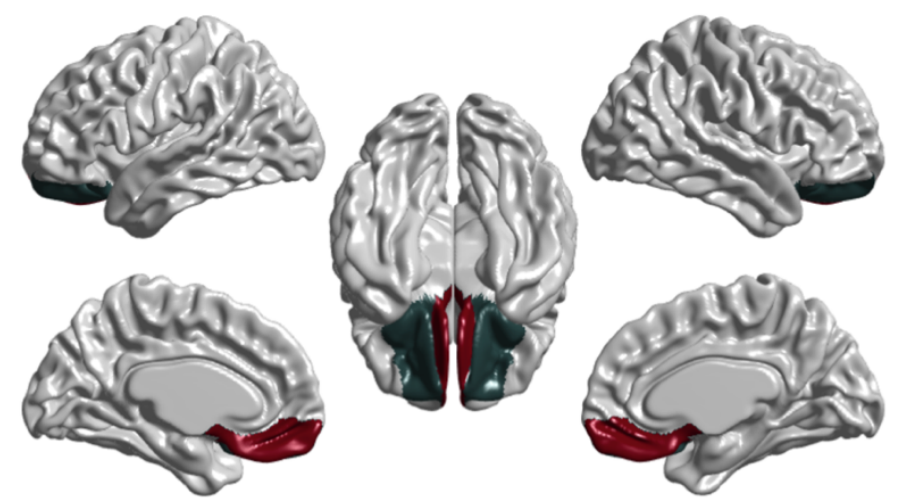

Figure 2. Association between cortical thickness and global negative symptoms in first-episode psychosis

FEP Zurich Sample ( $\mathrm{n}=26)$. For visualisation purpose, partial correlations between OFC thickness and BNSS Total scores are shown as Pearson correlation coefficients and two-tailed significance tests using R. Regressions were adjusted for age, sex, intracranial volume. Error shadings correspond to standard errors. adj., adjusted. Significant associations are observed in (a) right LOFC ( $\mathrm{rs}=-.624$, FDR-adjusted $\mathrm{p}=.02$ ) and (c) left $\mathrm{OFC}(\mathrm{rs}=-.613$, FDR-adjusted $\mathrm{p}=.02)$. Non-significant negative association are observed in (b) right MOFC ( $\mathrm{rs}=-.624$, FDR-adjusted $\mathrm{p}=.02)$ and $(\mathrm{d})$ left MOFC ( $\mathrm{rs}=-.624$, FDR-adjusted $\mathrm{p}=.02)$. (e) visualization of OFC parcellations in surface space, green= lateral OFC, red= medial OFC. 
medRxiv preprint doi: https://doi.org/10.1101/2020.04.07.20057166; this version posted April 10, 2020. The copyright holder for this preprint (which was not certified by peer review) is the author/funder, who has granted medRxiv a license to display the preprint in perpetuity. It is made available under a CC-BY-NC 4.0 International license .

Structural correlates of apathy and negative symptoms

\section{Group differences in striatal volume}

We examined group differences of striatal volume and OFC thickness within the schizophreniaspectrum across all studies $(\mathrm{n}=337)$. Using MANCOVA, we found a significant effect of group for striatal volumes $(\mathrm{F}(18,975)=6.66, \mathrm{p}<.0001$, Pillais Trace $=0.329)$. Univariate analyses of covariance revealed significant group differences in bilateral caudate, putamen, and left accumbens (Fig.3 Table 2B). Post-hoc pairwise comparisons showed a general pattern of greater caudate, putamen and accumbens volumes in patients with SZ compared to all other groups (Fig.3, Table 2B). Thus, patients with the longest duration of illness and long-term antipsychotic treatment displayed significant enlargement of striatal volumes.

To further explore effects of antipsychotic treatment on striatal volume in early disease stages, we divided the patients with FEP in one group of unmedicated FEP patients (FEP-NON) and one group of medicated FEP patients (FEP-MED) and performed an explorative post-hoc group comparison. FEP-MED ( $n=61)$ showed significant greater putamen volume (left: $p=.007$, right: $\mathrm{p}=.007$ ) and left NAcc volume (Laccumb: $\mathrm{p}<.001$, Raccumb: $\mathrm{p}=.067$ ) compared to FEP-NON $(\mathrm{n}=39)$ (Table S3).

Taken together, medicated patients with SZ showed the greatest enlargement in striatal volumes compared to all other groups. Additionally, medicated FEP displayed greater putamen and left NAcc volume compared to unmedicated FEP.

\section{Group differences in OFC thickness}

Regarding OFC thickness, MANCOVA revealed a significant effect of group for OFC thickness $(\mathrm{F}(12,984)=12.599, \mathrm{p}<.001$, Pillais Trace $=.399)$. Univariate analyses of covariance revealed significant group differences in bilateral LOFC and MOFC (Fig.3, Table 2B). Posthoc pairwise comparisons showed a general pattern of significantly thicker bilateral LOFC and MOFC in SPT compared to all other groups including HC. In addition, HC and FEP showed thicker OFC compared to SZ (Fig.3, Table 2B).

To further explore whether OFC thickness differences within the schizophrenia-spectrum might be related to onset of medication, we divided the FEP group in one unmedicated FEP patients' group (FEP-NON) and one medicated FEP patients (FEP-MED) group and performed an explorative group comparison. FEP-NON showed significantly thicker MOFC (left: $p=.002$, right: $\mathrm{p}=.005$ ) and LOFC (left: $\mathrm{p}=.001$, right: $\mathrm{p}=.005$ ) compared to FEP-MED (Table S4). Taken together, individuals with SPT displayed a pattern of thicker MOFC and left LOFC compared to all other groups (HC, FEP, SZ). In addition, FEP-NON showed thicker MOFC and LOFC compared to FEP-MED. 
medRxiv preprint doi: https://doi.org/10.1101/2020.04.07.20057166; this version posted April 10, 2020. The copyright holder for this preprint (which was not certified by peer review) is the author/funder, who has granted medRxiv a license to display the preprint in perpetuity. It is made available under a CC-BY-NC 4.0 International license.

Structural correlates of apathy and negative symptoms
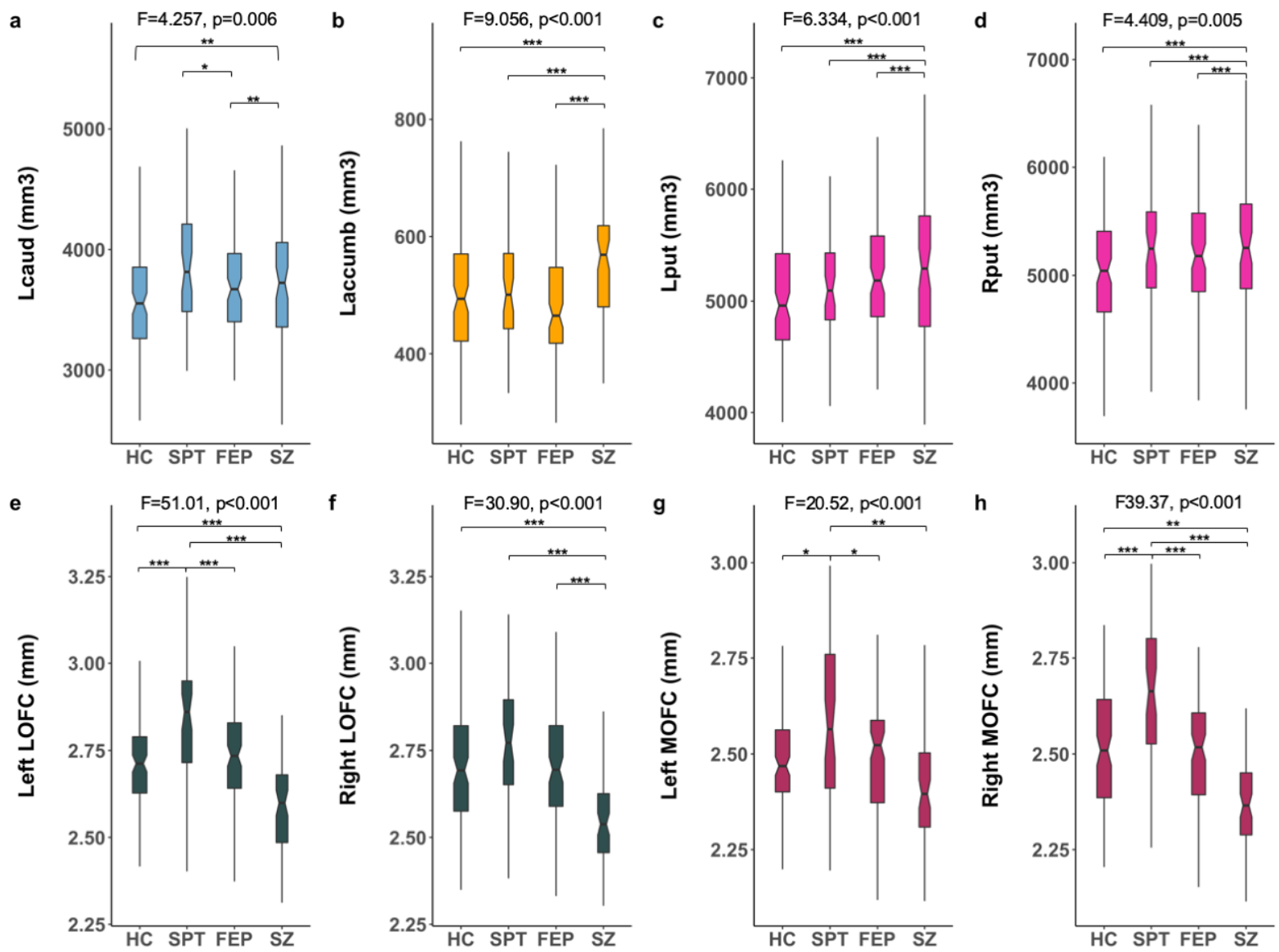

Figure 3. Group comparison of striatal volumes and OFC thickness across all sites $(\mathrm{n}=\mathbf{3 3 7})$

(a) Significant larger left caudate in SZ compared to HC and FEP ( $\mathrm{SZ}>\mathrm{HC}, \mathrm{p}=.004, \mathrm{SZ}>\mathrm{FEP}, \mathrm{p}=.003$ ). (b) Significant larger left accumbens and $(\mathrm{c}, \mathrm{d})$ bilateral putamen volume in $\mathrm{SZ}$ compared to all other groups ( $\mathrm{SZ}>\mathrm{HC}, \mathrm{SZ}>\mathrm{FEP}$, all $\mathrm{ps}<.001, \mathrm{SZ}>\mathrm{SPT}$ all ps $<.03$ ). (e) Significant greater left LOFC thickness in SPT compared to all other groups (all ps $<.001$ ) and greater left LOFC thickness in HC and FEP compared to SZ (all ps $<.001$ ). (f) Greater right LOFC thickness in HC, SPT , and FEP compared to SZ (HC $>$ SZ, SPT $>$ SZ, FEP $>$ SZ, allps $<.001)$. (g,h) Significant greater bilateral MOFC thickness in SPT compared to all other groups (all ps $<.02$ ) and greater right MOFC in $\mathrm{HC}$ compared to $\mathrm{SZ}(\mathrm{p}=.01)$. All post-hoc group tests Bonferroni corrected for multiple comparison $(\mathrm{p}<.05) . *<.05, * *<.01, * * *<.001$.

\section{Discussion}

\section{Summary}

This study revealed distinct orbitofrontal and striatal correlates of apathy and global negative symptoms across subgroups of the schizophrenia-spectrum. Reduced right NAcc and bilateral putamen volume correlated with apathy in unmedicated individuals with varying levels of SPT. This association was not observed in patient with FEP and SZ. In contrast, medicated patients (FEP,SZ) showed greater striatal volumes compared to unmedicated patients, SPT and HC. The relationship between OFC thickness and global negative symptoms revealed a different pattern. In patients with FEP, reduced LOFC thickness correlated with global negative symptoms. This association was not observed in unmedicated individuals with SPT, who showed an overall thicker OFC compared to all other groups including HC. In addition, medicated patients with 
medRxiv preprint doi: https://doi.org/10.1101/2020.04.07.20057166; this version posted April 10, 2020. The copyright holder for this preprint (which was not certified by peer review) is the author/funder, who has granted medRxiv a license to display the preprint in perpetuity. It is made available under a CC-BY-NC 4.0 International license .

Structural correlates of apathy and negative symptoms

FEP and SZ showed reduced OFC thickness compared to unmedicated FEP patients, unmedicated individuals with SPT and HC.

\section{Striatal volume}

To our knowledge this is the first study demonstrating a relationship between severity of apathy and reduced striatal volume in unmedicated populations of the schizophrenia-spectrum. This association was even detectable in a small sample of healthy individuals with low schizotypal personality traits (Montreal dataset). An association of reduced ventral striatal volume with apathy has been previously reported for patients with SZ. ${ }^{35,36}$ Together with these previous studies, our results suggest that reduced striatal volumes are a specific neuroanatomical correlate of the apathy dimension but not the diminished expression dimension. Previous negative results, derived from analyses using global negative symptom scores ${ }^{59,78}$, could be explained by lack of differentiation into distinct negative symptom dimensions. With respect to other subgroups of the schizophrenia-spectrum little data are available yet. In contrast to the lack of structural MRI work, fMRI studies provide converging evidence for blunted striatal reward signal as dimensional and transdiagnostic correlate of motivational and hedonic deficits. ${ }^{17,18,26,27,79}$ Our findings in unmedicated individuals with subclinical motivational and hedonic deficits extend this work, providing first evidence for striatal structural changes in the pathophysiology of apathy prior to clinical manifestation.

Contrary to the existing literature on $\mathrm{SZ}^{35,36}$ and our observation in unmedicated individuals with SPT, apathy was not related to reduced striatal volume in medicated patients with schizophrenia-spectrum disorders (FEP,SZ). Of note, medicated SZ and FEP patients showed overall larger striatal volumes compared to healthy individuals and non-medicated patients. Accumulating evidence from human and animal studies show that long-term antipsychotic medication leads to subcortical grey matter enlargement. ${ }^{80}$ Are volumetric changes due to antipsychotic treatment or other disease-related processes responsible for our negative results? Within the schizophrenia-spectrum and compared to HC, medicated patients showed larger caudate, putamen and left accumbens volume. Observations of larger caudate and putamen volume (but not accumbens volume) in patients with SZ are consistent with two recent metaanalyses. ${ }^{59,81}$ Our results are also consistent with previous reports showing positive associations between larger striatal volumes and current medication dose as well as illness duration. ${ }^{59,82,83}$ In addition, longitudinal studies demonstrated that caudate and putamen volume increase after initiation of antipsychotic treatment in non-medicated or minimally treated patients. ${ }^{84-87}$ Our findings in FEP point in the same direction showing larger striatal volumes in medicated compared to unmedicated FEP patients. Although cross-sectional data do not allow causal inference, it is possible that in medicated patients associations between reduced striatal volumes and apathy are obscured by antipsychotic-induced volume changes.

\section{Orbitofrontal grey matter thickness}

The present study revealed a dimensional association between global negative symptoms and reduced lateral OFC thickness in patients with FEP. The association between left lateral OFC thickness and global negative symptoms was replicated in an independent dataset of patients with FEP. In this regard, a recent meta-analysis provided evidence for an association between 
medRxiv preprint doi: https://doi.org/10.1101/2020.04.07.20057166; this version posted April 10, 2020. The copyright holder for this preprint (which was not certified by peer review) is the author/funder, who has granted medRxiv a license to display the preprint in perpetuity. It is made available under a CC-BY-NC 4.0 International license .

Structural correlates of apathy and negative symptoms

reduced medial and lateral OFC thickness and global negative symptoms in chronic SZ. ${ }^{37}$ Our data contribute and extend this finding demonstrating a dimensional relationship between OFC thickness and negative symptoms in FEP patients and a trend level effect in SZ patients. Importantly, this association was apparent in a mixed FEP sample (brief psychotic disorder and first-episode SZ, Zurich Dataset) and also in a minimally treated brief psychotic disorder sample (Basel Dataset). These results are consistent with two previous reports in smaller samples comparing patients with persistent $(\mathrm{n}<20)$ and non-persistent negative symptoms $(\mathrm{n}<55) .{ }^{41,42}$ Together with these studies, our data suggest that the association between orbitofrontal structural abnormalities and negative symptoms can occur early in the disease process prior to the diagnosis of SZ. Furthermore, the association with global negative symptoms suggest a more general role of structural OFC abnormalities in the manifestation of negative symptoms rather than a specific mechanism related to a distinct negative symptom dimension or domain.

It is important to note that some previous studies investigating negative symptoms and structural abnormalities in at-risk stages and first-episode psychosis have been inconclusive. ${ }^{40,88-90}$. As discussed by Walton and colleagues ${ }^{37}$, one possible explanation could be that the association between negative symptoms and OFC thickness is less prominent in earlier disease stages. Additionally, using the PANSS Negative scores rather than specific assessment such as the SANS or newly developed scales (e.g. BNSS, CAINS ${ }^{91}$ ) could be another explanation for the failure of previous studies to detect an association between OFC thickness and negative symptoms. A different explanation might be that associations between negative symptoms and reduced OFC thickness are only prevalent in specific subgroups of the schizophrenia-spectrum. This could explain why we did not observe the same pattern in individuals with SPT, showing no association with LOFC thickness and even an inverse trendlevel association with greater right MOFC thickness in those with higher negative symptoms.

In accordance with the latter argument, group comparison revealed a consistent pattern of greater LOFC and MOFC thickness in individuals with SPT compared to HC as well as FEP and SZ patients. A recent report comparing high schizotypy and low schizotypy found reduced volume and thickness predominantly in the temporal and some frontal regions but sparing the OFC. ${ }^{92}$ Interestingly, greater OFC thickness has also been observed in drug-naïve first-episode patients with SZ compared to $\mathrm{HC} .{ }^{88,90}$ Our results contribute to this literature, showing thicker OFC in drug-naïve FEP patients compared to medicated patients (FEP, SZ). The nature of preserved or greater prefrontal cortical thickness and volume in early stages of the schizophrenia-spectrum is the subject of intense debate. One prominent hypothesis proposes that preserved/greater prefrontal cortical thickness reflects a compensatory mechanism protecting individuals with SPT from transition to SZ. ${ }^{38,88,92,93}$ A similar mechanism could explain thicker OFC in FEP patients with less severe symptom burden and less need for antipsychotic treatment. Alternatively, greater cortical thickness in specific brain regions could be the consequence of abnormal cortical development during maturation due to insufficient synaptic pruning and/or deficient myelination. ${ }^{88,94,95}$ Such microstructural deficits would therefore contribute to a higher vulnerability in at-risk stages, with SZ only emerging in the presence of additional environmental, biological or genetic factors. ${ }^{94,96}$ Of note, this model does not contradict findings of reduced gray matter in some brain regions. Distinct biological processes may propagate as diverse, heterochronic and distributed effects, thus contributing to the complex neuroanatomical pattern. In this regard, future large-scale longitudinal studies are 
medRxiv preprint doi: https://doi.org/10.1101/2020.04.07.20057166; this version posted April 10, 2020. The copyright holder for this preprint (which was not certified by peer review) is the author/funder, who has granted medRxiv a license to display the preprint in perpetuity. It is made available under a CC-BY-NC 4.0 International license .

Structural correlates of apathy and negative symptoms

needed to clarify the origin of these dynamic cortical changes evolving across non-clinical to clinical manifestation within the schizophrenia-spectrum.

\section{Limitation and future directions}

Capitalizing on data from four different sites we aimed to replicate and extend findings on morphometric correlates of negative symptoms for different subgroups of the schizophreniaspectrum. However, sample sizes within each study and subgroup were rather small and replication in larger cohorts is needed. Negative symptom measures across studies were heterogenous and only one study was a priori designed to investigate the full schizophreniaspectrum (Zurich dataset) and employed the same negative symptom measures in all subgroups. In addition, this study was the only one that included criteria to minimize the inclusion of secondary negative symptoms related to other sources such as depression. ${ }^{97,98}$ Potential confounding effects of secondary negative symptoms can be assumed in FEP patients from the Basel dataset, where a depressive episode was not an exclusion criterion. In this regard, it will be critical to systematically account for primary and secondary negative symptoms and harmonize psychopathological measures across non-clinical and clinical populations to enable large-scale transdiagnostic approaches crossing boundaries between non-clinical and clinical stages.

\section{Conclusion}

Employing a schizophrenia-spectrum approach, we identified distinct orbitofrontal and striatal structural correlates of negative symptoms in non-clinical/unmedicated populations and early psychosis. Our findings suggest that negative symptoms associate with a temporal continuum of orbitofrontal-striatal abnormalities that may predate the occurrence of schizophrenia. Combining data from four different sites, two divergent neuroanatomical orbitofrontal-striatal patterns emerged along a disease severity axis. One pattern reflected greater striatal volumes in those with chronic disease and exposure to antipsychotic medication, while a second revealed greater OFC thickness in those with subclinical psychotic traits and unmedicated early disease stages. 
medRxiv preprint doi: https://doi.org/10.1101/2020.04.07.20057166; this version posted April 10, 2020. The copyright holder for this preprint (which was not certified by peer review) is the author/funder, who has granted medRxiv a license to display the preprint in perpetuity. It is made available under a CC-BY-NC 4.0 International license .

Structural correlates of apathy and negative symptoms

\section{Conflict of interests}

Stefan Kaiser has received speaker honoraria from Roche, Lundbeck, Janssen and Takeda. He receives royalties for cognitive test and training software from Schuhfried. Philippe Tobler has received grant support from Pfizer. Erich Seifritz has received grant support from H. Lundbeck and has served as a consultant and/or speaker for AstraZeneca, Otsuka, Takeda, Eli Lilly, Janssen, Lundbeck, Novartis, Pfizer, Roche, and Servier. None of these activities are related to the present study. All other authors declare no biomedical financial interests or potential conflicts of interest.

\section{Acknowledgments}

Matthias Kirschner acknowledges support from the National Bank Fellowship (McGill University) and the Swiss National Foundation (P2SKP3_178175). The authors thank Dr. Casey Paquola for her helpful insight on the manuscript and excellent support, and all patients and healthy volunteers for their participation.

\section{References}

1. Strauss, G. P. \& Cohen, A. S. A Transdiagnostic Review of Negative Symptom Phenomenology and Etiology. Schizophr. Bull. 43, 712-719 (2017).

2. Konings, M., Bak, M., Hanssen, M., van Os, J. \& Krabbendam, L. Validity and reliability of the CAPE: a self-report instrument for the measurement of psychotic experiences in the general population. Acta Psychiatr Scand 114, 55-61 (2006).

3. Barrantes-Vidal, N., Grant, P. \& Kwapil, T. R. The role of schizotypy in the study of the etiology of schizophrenia spectrum disorders. Schizophr. Bull. 41 Suppl 2, S408-416 (2015).

4. Fonseca-Pedrero, E. et al. The structure of schizotypal personality traits: a cross-national study. Psychol. Med. 48, 451-462 (2018).

5. Galderisi, S., Mucci, A., Buchanan, R. W. \& Arango, C. Negative symptoms of schizophrenia: new developments and unanswered research questions. Lancet Psychiatry (2018) doi:10.1016/S2215-0366(18)30050-6.

6. Blanchard, J. J. \& Cohen, A. S. The structure of negative symptoms within schizophrenia: implications for assessment. Schizophr. Bull. 32, 238-245 (2006).

7. Foussias, G. \& Remington, G. Negative Symptoms in Schizophrenia: Avolition and Occam's Razor. Schizophr Bull 36, 359-369 (2010).

8. Faerden, A. et al. Apathy, poor verbal memory and male gender predict lower psychosocial functioning one year after the first treatment of psychosis. Psychiatry Res. 210, 55-61 (2013).

9. Galderisi, S. et al. Categorical and dimensional approaches to negative symptoms of schizophrenia: focus on long-term stability and functional outcome. Schizophr. Res. 147, 157-162 (2013). 
medRxiv preprint doi: https://doi.org/10.1101/2020.04.07.20057166; this version posted April 10, 2020. The copyright holder for this preprint (which was not certified by peer review) is the author/funder, who has granted medRxiv a license to display the preprint in perpetuity. It is made available under a CC-BY-NC 4.0 International license.

Structural correlates of apathy and negative symptoms

10. Strauss, G. P. et al. Deconstructing negative symptoms of schizophrenia: avolition-apathy and diminished expression clusters predict clinical presentation and functional outcome. $J$. Psychiatr. Res. 47, 783-790 (2013).

11. Fervaha, G., Foussias, G., Agid, O. \& Remington, G. Motivational and neurocognitive deficits are central to the prediction of longitudinal functional outcome in schizophrenia. Acta Psychiatr. Scand. 130, 290-299 (2014).

12. Kos, C., van Tol, M.-J., Marsman, J.-B. C., Knegtering, H. \& Aleman, A. Neural correlates of apathy in patients with neurodegenerative disorders, acquired brain injury, and psychiatric disorders. Neurosci. Biobehav. Rev. 69, 381-401 (2016).

13. Barch, D. M. \& Dowd, E. C. Goal Representations and Motivational Drive in Schizophrenia: The Role of Prefrontal-Striatal Interactions. Schizophr. Bull. 36, 919-934 (2010).

14. Strauss, G. P., Waltz, J. A. \& Gold, J. M. A Review of Reward Processing and Motivational Impairment in Schizophrenia. Schizophr. Bull. 40, S107-S116 (2014).

15. Radua, J. et al. Ventral Striatal Activation During Reward Processing in Psychosis: A Neurofunctional Meta-Analysis. JAMA Psychiatry 1243-1251

(2015) doi:10.1001/jamapsychiatry.2015.2196.

16. Maia, T. V. \& Frank, M. J. An Integrative Perspective on the Role of Dopamine in Schizophrenia. Biol. Psychiatry 81, 52-66 (2017).

17. Kirschner, M. et al. Ventral striatal hypoactivation is associated with apathy but not diminished expression in patients with schizophrenia. J. Psychiatry Neurosci. JPN 40, 140383 (2015).

18. Mucci, A. et al. Is avolition in schizophrenia associated with a deficit of dorsal caudate activity? A functional magnetic resonance imaging study during reward anticipation and feedback. Psychol. Med. 1-14 (2015) doi:10.1017/S0033291714002943.

19. Stepien, M. et al. Investigating the association of ventral and dorsal striatal dysfunction during reward anticipation with negative symptoms in patients with schizophrenia and healthy individuals. PloS One 13, e0198215 (2018).

20. Waltz, J. A. et al. Abnormal responses to monetary outcomes in cortex, but not in the basal ganglia, in schizophrenia. Neuropsychopharmacology 35, 2427-39 (2011).

21. Simon, J. J. et al. Neural correlates of reward processing in schizophrenia - Relationship to apathy and depression. Schizophr. Res. 118, 154-161 (2010).

22. Moran, E. K., Culbreth, A. J., Kandala, S. \& Barch, D. M. From neuroimaging to daily functioning: A multimethod analysis of reward anticipation in people with schizophrenia. J. Abnorm. Psychol. (2019) doi:10.1037/abn0000461.

23. Dowd, E. C., Frank, M. J., Collins, A., Gold, J. M. \& Barch, D. M. Probabilistic Reinforcement Learning in Patients With Schizophrenia: Relationships to Anhedonia and Avolition. Biol. Psychiatry Cogn. Neurosci. Neuroimaging 1, 460-473 (2016).

24. Waltz, J. A. et al. Motivational Deficits in Schizophrenia Are Associated With Reduced Differentiation Between Gain and Loss-Avoidance Feedback in the Striatum. Biol. Psychiatry Cogn. Neurosci. Neuroimaging 3, 239-247 (2018).

25. Dowd, E. C. \& Barch, D. M. Pavlovian reward prediction and receipt in schizophrenia: relationship to anhedonia. PloS One 7, e35622 (2012). 
medRxiv preprint doi: https://doi.org/10.1101/2020.04.07.20057166; this version posted April 10, 2020. The copyright holder for this preprint (which was not certified by peer review) is the author/funder, who has granted medRxiv a license to display the preprint in perpetuity. It is made available under a CC-BY-NC 4.0 International license.

Structural correlates of apathy and negative symptoms

26. Simon, J. J. et al. Reward System Dysfunction as a Neural Substrate of Symptom Expression Across the General Population and Patients With Schizophrenia. Schizophr. Bull. 41, 1370-1378 (2015).

27. Wotruba, D. et al. Symptom dimensions are associated with reward processing in unmedicated persons at risk for psychosis. Front. Behav. Neurosci. 8, 382 (2014).

28. Knolle, F. et al. Brain responses to different types of salience in antipsychotic naïve first episode psychosis: An fMRI study. Transl. Psychiatry 8, 196 (2018).

29. Nielsen, M. Ø. et al. Alterations of the Brain Reward System in Antipsychotic Naïve Schizophrenia Patients. Biol. Psychiatry 71, 898-905 (2012).

30. Kirschner, M. et al. Ventral Striatal Dysfunction and Symptom Expression in Individuals With Schizotypal Personality Traits and Early Psychosis. Schizophr. Bull. (2016) doi:10.1093/schbul/sbw142.

31. Segarra, N. et al. Abnormal Frontostriatal Activity During Unexpected Reward Receipt in Depression and Schizophrenia: Relationship to Anhedonia. Neuropsychopharmacol. Off. Publ. Am. Coll. Neuropsychopharmacol. (2015) doi:10.1038/npp.2015.370.

32. Kluge, A. et al. Combining actigraphy, ecological momentary assessment and neuroimaging to study apathy in patients with schizophrenia. Schizophr. Res. (2017) doi:10.1016/j.schres.2017.09.034.

33. Li, Y. et al. Grey matter reduction in the caudate nucleus in patients with persistent negative symptoms: An ALE meta-analysis. Schizophr. Res. 192, 9-15 (2018).

34. Hovington, C. L. \& Lepage, M. Neurocognition and neuroimaging of persistent negative symptoms of schizophrenia. Expert Rev. Neurother. 12, 53-69 (2012).

35. Roth, R. M. et al. Apathy Is Associated With Ventral Striatum Volume in Schizophrenia Spectrum Disorder. J. Neuropsychiatry Clin. Neurosci. 28, 191-194 (2016).

36. Caravaggio, F. et al. Amotivation is associated with smaller ventral striatum volumes in older patients with schizophrenia. Int. J. Geriatr. Psychiatry 33, 523-530 (2018).

37. Walton, E. et al. Prefrontal cortical thinning links to negative symptoms in schizophrenia via the ENIGMA consortium. Psychol. Med. 48, 82-94 (2018).

38. Kühn, S., Schubert, F. \& Gallinat, J. Higher prefrontal cortical thickness in high schizotypal personality trait. J. Psychiatr. Res. 46, 960-965 (2012).

39. Nenadic, I. et al. Brain structural correlates of schizotypy and psychosis proneness in a nonclinical healthy volunteer sample. Schizophr. Res. 168, 37-43 (2015).

40. McKechanie, A. G. et al. Negative symptoms and longitudinal grey matter tissue loss in adolescents at risk of psychosis: preliminary findings from a 6-year follow-up study. Br. $J$. Psychiatry J. Ment. Sci. 208, 565-570 (2016).

41. Bodnar, M. et al. Cortical Thinning in Temporo-Parietal Junction (TPJ) in Non-Affective First-Episode of Psychosis Patients with Persistent Negative Symptoms. PLOS ONE 9, e101372 (2014).

42. Mørch-Johnsen, L. et al. Brain structure abnormalities in first-episode psychosis patients with persistent apathy. Schizophr. Res. 164, 59-64 (2015).

43. Venkatasubramanian, G., Jayakumar, P. N., Gangadhar, B. N. \& Keshavan, M. S. Automated MRI parcellation study of regional volume and thickness of prefrontal cortex (PFC) in antipsychotic-naïve schizophrenia. Acta Psychiatr. Scand. 117, 420-431 (2008). 
medRxiv preprint doi: https://doi.org/10.1101/2020.04.07.20057166; this version posted April 10, 2020. The copyright holder for this preprint (which was not certified by peer review) is the author/funder, who has granted medRxiv a license to display the preprint in perpetuity. It is made available under a CC-BY-NC 4.0 International license.

Structural correlates of apathy and negative symptoms

44. van Erp, T. G. M. et al. Cortical Brain Abnormalities in 4474 Individuals With Schizophrenia and 5098 Control Subjects via the Enhancing Neuro Imaging Genetics Through Meta Analysis (ENIGMA) Consortium. Biol. Psychiatry 84, 644-654 (2018).

45. Fusar-Poli, P. et al. Progressive brain changes in schizophrenia related to antipsychotic treatment? A meta-analysis of longitudinal MRI studies. Neurosci. Biobehav. Rev. 37, 1680-1691 (2013).

46. Fervaha, G. \& Remington, G. Neuroimaging findings in schizotypal personality disorder: a systematic review. Prog. Neuropsychopharmacol. Biol. Psychiatry 43, 96-107 (2013).

47. Raine, A. The SPQ: a scale for the assessment of schizotypal personality based on DSMIII-R criteria. Schizophr. Bull. 17, 555-564 (1991).

48. Soliman, A. et al. Limbic response to psychosocial stress in schizotypy: a functional magnetic resonance imaging study. Schizophr. Res. 131, 184-191 (2011).

49. Chapman, L. J., Edell, W. S. \& Chapman, J. P. Physical anhedonia, perceptual aberration, and psychosis proneness. Schizophr. Bull. 6, 639-653 (1980).

50. Chapman, L. J., Chapman, J. P. \& Raulin, M. L. Scales for physical and social anhedonia. J Abnorm Psychol 85, 374-82 (1976).

51. Bykowsky, O. et al. Association of antidepressants with brain morphology in early stages of psychosis: an imaging genomics approach. Sci. Rep. 9, 8516 (2019).

52. Das, T. et al. Disorganized Gyrification Network Properties During the Transition to Psychosis. JAMA Psychiatry 75, 613-622 (2018).

53. Dukart, J. et al. Age-related brain structural alterations as an intermediate phenotype of psychosis. J. Psychiatry Neurosci. JPN 42, 307-319 (2017).

54. Avram, M. et al. Reduced striatal dopamine synthesis capacity in patients with schizophrenia during remission of positive symptoms. Brain 142, 1813-1826 (2019).

55. Andreasen, N. C. et al. Remission in schizophrenia: proposed criteria and rationale for consensus. Am. J. Psychiatry 162, 441-449 (2005).

56. Fischl, B. FreeSurfer. NeuroImage 62, 774-781 (2012).

57. Fischl, B. et al. Whole Brain Segmentation: Automated Labeling of Neuroanatomical Structures in the Human Brain. Neuron 33, 341-355 (2002).

58. Desikan, R. S. et al. An automated labeling system for subdividing the human cerebral cortex on MRI scans into gyral based regions of interest. NeuroImage 31, 968-980 (2006).

59. van Erp, T. G. M. et al. Subcortical brain volume abnormalities in 2028 individuals with schizophrenia and 2540 healthy controls via the ENIGMA consortium. Mol. Psychiatry 21, 547-553 (2016).

60. Hibar, D. P. et al. Cortical abnormalities in bipolar disorder: an MRI analysis of 6503 individuals from the ENIGMA Bipolar Disorder Working Group. Mol. Psychiatry 23, 932942 (2018).

61. Walton, E. et al. Positive symptoms associate with cortical thinning in the superior temporal gyrus via the ENIGMA-Schizophrenia consortium. Acta Psychiatr. Scand. 135, 439-447 (2017).

62. Kirkpatrick, B. et al. The brief negative symptom scale: psychometric properties. Schizophr Bull 37, 300-5 (2011).

63. Strauss, G. P. et al. FACTOR STRUCTURE OF THE BRIEF NEGATIVE SYMPTOM SCALE. Schizophr. Res. 142, 96-98 (2012). 
medRxiv preprint doi: https://doi.org/10.1101/2020.04.07.20057166; this version posted April 10, 2020. The copyright holder for this preprint (which was not certified by peer review) is the author/funder, who has granted medRxiv a license to display the preprint in perpetuity. It is made available under a CC-BY-NC 4.0 International license .

Structural correlates of apathy and negative symptoms

64. Bischof, M. et al. The brief negative symptom scale: validation of the German translation and convergent validity with self-rated anhedonia and observer-rated apathy. $B M C$ Psychiatry 16, 415 (2016).

65. Mucci, A. et al. The Brief Negative Symptom Scale (BNSS): Independent validation in a large sample of Italian patients with schizophrenia. Eur. Psychiatry J. Assoc. Eur. Psychiatr. 30, 641-647 (2015).

66. Kirkpatrick, B., Fenton, W. S., Carpenter, W. T., Jr. \& Marder, S. R. The NIMH-MATRICS consensus statement on negative symptoms. Schizophr Bull 32, 214-9 (2006).

67. Strauss, G. P. et al. The Latent Structure of Negative Symptoms in Schizophrenia. JAMA Psychiatry 75, 1271-1279 (2018).

68. Ahmed, A. O. et al. Cross-cultural Validation of the 5-Factor Structure of Negative Symptoms in Schizophrenia. Schizophr. Bull. 45, 305-314 (2019).

69. Strauss, G. P. et al. Network Analysis Reveals the Latent Structure of Negative Symptoms in Schizophrenia. Schizophr. Bull. 45, 1033-1041 (2019).

70. Wolf, D. H. et al. Amotivation in Schizophrenia: Integrated Assessment With Behavioral, Clinical, and Imaging Measures. Schizophr. Bull. sbu026 (2014) doi:10.1093/schbul/sbu026.

71. Andreasen, N. C. The Scale for the Assessment of Negative Symptoms (SANS): Conceptual and Theoretical Foundations. Br. J. Psychiatry 155, 49-52 (1989).

72. Marder, S. R., Davis, J. M. \& Chouinard, G. The effects of risperidone on the five dimensions of schizophrenia derived by factor analysis: combined results of the North American trials. J. Clin. Psychiatry 58, 538-546 (1997).

73. Revelle, W. R. psych: Procedures for Personality and Psychological Research. (2017).

74. R Core Team. $R$ : A Language and Environment for Statistical Computing. (R Foundation for Statistical Computing, 2013).

75. Benjamini, Y. \& Hochberg, Y. Controlling the False Discovery Rate: A Practical and Powerful Approach to Multiple Testing. J. R. Stat. Soc. Ser. B Methodol. 57, 289-300 (1995).

76. Selker, R., Love, J. \& Dropmann, D. jmv: The 'jamovi' Analyses. (2019).

77. Steiger, J. H. Tests for comparing elements of a correlation matrix. Psychol. Bull. 87, 245251 (1980).

78. Ehrlich, S. et al. Striatal function in relation to negative symptoms in schizophrenia. Psychol. Med. 42, 267-282 (2012).

79. Hägele, C. et al. Dimensional psychiatry: reward dysfunction and depressive mood across psychiatric disorders. Psychopharmacology (Berl.) 1-11 (2014) doi:10.1007/s00213-0143662-7.

80. Amato, D., Beasley, C. L., Hahn, M. K. \& Vernon, A. C. Neuroadaptations to antipsychotic drugs: Insights from pre-clinical and human post-mortem studies. Neurosci. Biobehav. Rev. 76, 317-335 (2017).

81. Okada, N. et al. Abnormal asymmetries in subcortical brain volume in schizophrenia. Mol. Psychiatry 21, 1460-1466 (2016).

82. Haijma, S. V. et al. Brain volumes in schizophrenia: a meta-analysis in over 18000 subjects. Schizophr. Bull. 39, 1129-1138 (2013).

83. Hashimoto, N. et al. The effect of duration of illness and antipsychotics on subcortical volumes in schizophrenia: Analysis of 778 subjects. NeuroImage Clin. 17, 563-569 (2017). 
medRxiv preprint doi: https://doi.org/10.1101/2020.04.07.20057166; this version posted April 10, 2020. The copyright holder for this preprint (which was not certified by peer review) is the author/funder, who has granted medRxiv a license to display the preprint in perpetuity. It is made available under a CC-BY-NC 4.0 International license.

Structural correlates of apathy and negative symptoms

84. Glenthoj, A. et al. Basal ganglia volumes in drug-naive first-episode schizophrenia patients before and after short-term treatment with either a typical or an atypical antipsychotic drug. Psychiatry Res. 154, 199-208 (2007).

85. Ho, B.-C., Andreasen, N. C., Ziebell, S., Pierson, R. \& Magnotta, V. Long-term Antipsychotic Treatment and Brain Volumes. Arch. Gen. Psychiatry 68, 128-137 (2011).

86. Li, M. et al. Volume increases in putamen associated with positive symptom reduction in previously drug-naive schizophrenia after 6 weeks antipsychotic treatment. Psychol. Med. 42, 1475-1483 (2012).

87. Homan, P. et al. Striatal volume and functional connectivity correlate with weight gain in early-phase psychosis. Neuropsychopharmacology 44, 1948-1954 (2019).

88. Xiao, Y. et al. Altered Cortical Thickness Related to Clinical Severity But Not the Untreated Disease Duration in Schizophrenia. Schizophr. Bull. 41, 201-210 (2015).

89. Ansell, B. R. E. et al. Divergent effects of first-generation and second-generation antipsychotics on cortical thickness in first-episode psychosis. Psychol. Med. 45, 515-527 (2015).

90. Ren, W. et al. Anatomical and functional brain abnormalities in drug-naive first-episode schizophrenia. Am. J. Psychiatry 170, 1308-1316 (2013).

91. Horan, W. P., Kring, A. M., Gur, R. E., Reise, S. P. \& Blanchard, J. J. Development and psychometric validation of the Clinical Assessment Interview for Negative Symptoms (CAINS). Schizophr. Res. 132, 140-145 (2011).

92. DeRosse, P. et al. Evidence from structural and diffusion tensor imaging for frontotemporal deficits in psychometric schizotypy. Schizophr. Bull. 41, 104-114 (2015).

93. Siever, L. J. \& Davis, K. L. The pathophysiology of schizophrenia disorders: perspectives from the spectrum. Am. J. Psychiatry 161, 398-413 (2004).

94. Insel, T. R. Rethinking schizophrenia. Nature 468, 187-193 (2010).

95. Rapoport, J., Giedd, J. \& Gogtay, N. Neurodevelopmental model of schizophrenia: update 2012. Mol. Psychiatry 17, 1228-1238 (2012).

96. Smieskova, R. et al. Neuroimaging predictors of transition to psychosis--a systematic review and meta-analysis. Neurosci Biobehav Rev 34, 1207-22 (2010).

97. Carpenter, W. T., Jr., Heinrichs, D. W. \& Alphs, L. D. Treatment of negative symptoms. Schizophr Bull 11, 440-52 (1985).

98. Kirschner, M., Aleman, A. \& Kaiser, S. Secondary negative symptoms - A review of mechanisms, assessment and treatment. Schizophr. Res. (2016) doi:10.1016/j.schres.2016.05.003. 


\section{Tables}

Table 1. Demographic, Psychopathological and Clinical Data

\begin{tabular}{|c|c|c|c|c|c|}
\hline Complete (all studies, $\mathbf{n = 3 3 7 )}$ & HC $(n=111)$ & SPT $(n=52)$ & $\operatorname{FEP}(n=100)$ & $\mathrm{SZ}(\mathrm{n}=74)$ & Test Statistic $\left(\mathrm{U} / \mathrm{F} / \mathbf{x}^{2}\right)$ \\
\hline Age & $29.3(7.5)$ & $24.7(8.8)$ & $26.2(6.8)$ & $36.3(10.4)$ & $\mathrm{F}=23.5^{* *}$ \\
\hline $\operatorname{Sex}(\mathrm{f} / \mathrm{m})$ & $46 / 41$ & $28 / 24$ & $22 / 78$ & $21 / 53$ & $\mathrm{x} 2=27.6^{* * * *}$ \\
\hline Handedness, $(\mathrm{r} / \mathrm{l} / \mathrm{both})(\mathrm{n}=286)$ & $72 / 12 / 3$ & $45 / 5 / 2$ & $90 / 9$ & $42 / 6$ & \\
\hline GAF $(n=202)$ & $90.3(4.7)(n=44)$ & $71.0(11.1)(\mathrm{n}=27)$ & $59.2(14.1)(n=96)$ & $56.2(9.5)$ & $\mathrm{F}=104.0 * * * *$ \\
\hline Study I (Zurich) & HC $(n=28)$ & SPT $(n=27)$ & $\operatorname{FEP}(n=26)$ & $\mathrm{SZ}(\mathrm{n}=48)$ & \\
\hline Age & $32.5(9.3)$ & $29.1(10.3)$ & $24.3(7.0)$ & $32.81(7.86)$ & $\mathrm{F}=6.3 * *$ \\
\hline $\operatorname{Sex}(\mathrm{f} / \mathrm{m})$ & $10 / 18$ & $10 / 17$ & $5 / 21$ & $13 / 35$ & $\mathrm{x} 2=2.7$ \\
\hline Education, Years & $13.5(2.5)$ & $15.3(2.5)$ & $12.2(2.6)$ & $12.05(2.62)$ & $\mathrm{F}=5.6^{* * *}$ \\
\hline MWT IQ & $27.4(3.8)$ & $27.5(3.4)$ & $22.7(5.8)$ & & $\mathrm{F}=1.2 * * *$ \\
\hline Duration of illness, years & & & $0.5(0.5)$ & $10.33(6.80)$ & \\
\hline Duration of antipsychotic treatment in days & & & $41(30)$ & & \\
\hline Diagnosis (SZ/BPD) ${ }^{\mathrm{a}}$ & & & $13 / 13$ & $8 / 40$ & \\
\hline Chlorpromazine Equivalents (mg/d) & & & $288.7(261.2)$ & $521.13(416.07)$ & \\
\hline BNSS Apathy ${ }^{b}$ & & $8.5(8.2)$ & $13.8(8.1)$ & $15.40(8.40)$ & $\mathrm{U}=215.5^{*}$ \\
\hline BNSS Diminished Expression ${ }^{c}$ & & $3.2(4.4)$ & $7.0(7.4)$ & $8.10(7.46)$ & $\mathrm{U}=252.0$ \\
\hline BNSS Total & & $12.2(8.3)$ & $21.4(12.8)$ & $24.13(13.10)$ & $\mathrm{U}=202.5 * *$ \\
\hline PANSS Positive Factor ${ }^{\mathrm{d}}$ & & $5.4(2.3)$ & $5.9(1.8)$ & $10.92(2.75)$ & $\mathrm{U}=269.5$ \\
\hline CDSS Total & & $2.0(2.1)$ & $1.8(2.4)$ & $1.73(2.10)$ & $\mathrm{U}=307.5$ \\
\hline Cognition Score ${ }^{\mathrm{e}}$ & $0(.48)$ & $.64(.64)$ & $-.27(.62)$ & & $\mathrm{F}=16.3 * * *$ \\
\hline GAF & & $71.0(11.1)$ & $63.6(10.3)$ & $56.2(9.5)$ & \\
\hline Study II (Montreal) & HC $(n=15)$ & Pos SPT $(n=13)$ & Neg SPT $(n=12)$ & & \\
\hline Age & $19.6(0.9)$ & $19.6(0.9)$ & $19.6(0.9)$ & & $\mathrm{F}=1.1$ \\
\hline $\operatorname{Sex}(\mathrm{f} / \mathrm{m})$ & $9 / 6$ & $9 / 6$ & $9 / 6$ & & $\mathrm{x} 2=.62$ \\
\hline PerAb & $2.1(1.7)$ & $20.7(4.9)$ & $5(4.6)$ & & $\mathrm{x}^{2}=27.1 * * * *$ \\
\hline
\end{tabular}


Structural Correlates of negative symptoms

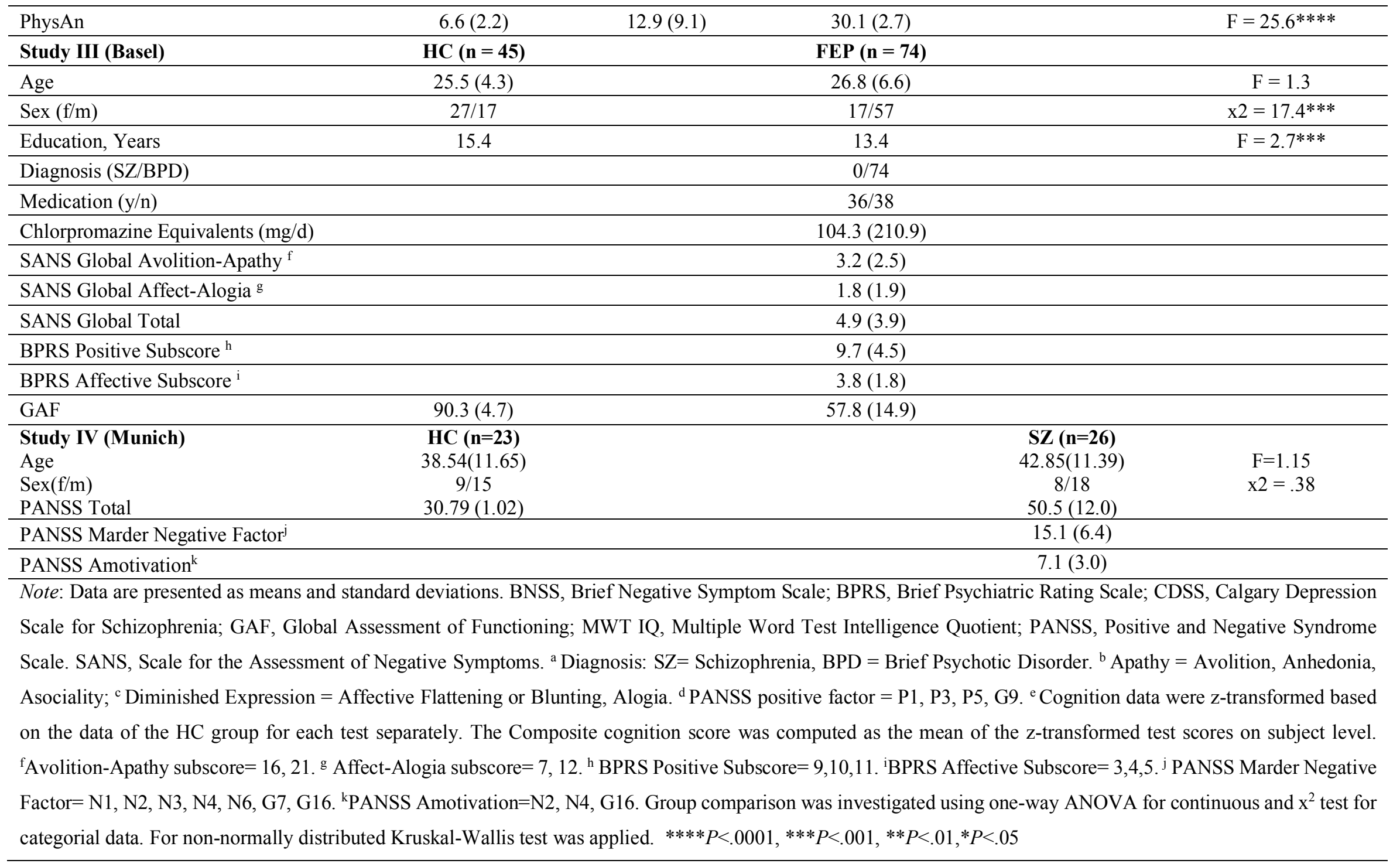


Structural Correlates of negative symptoms

Table 2A. Spearman Correlation between Apathy and striatal ROIs and global negative symptoms and cortical ROIs

\begin{tabular}{|c|c|c|c|c|c|c|}
\hline \multirow[b]{2}{*}{ BNSS Apathy } & \multicolumn{2}{|c|}{ SPT $(n=27)$} & \multicolumn{2}{|c|}{$\operatorname{FEP}(n=26)$} & \multicolumn{2}{|c|}{$\mathrm{SZ}(\mathrm{n}=48)$} \\
\hline & rs & adj p-value & rs & adj p-value & rs & adj p-value \\
\hline $\mathrm{R}$ accumbens & -0.538 & 0.02 & -0.043 & 0.95 & 0.016 & 0.90 \\
\hline L accumbens & -0.378 & 0.19 & 0.112 & 0.90 & 0.112 & 0.80 \\
\hline $\mathrm{R}$ putamen & -0.582 & 0.01 & 0.058 & 0.95 & 0.053 & 0.90 \\
\hline $\mathrm{L}$ putamen & -0.632 & 0.009 & 0.162 & 0.80 & 0.078 & 0.80 \\
\hline $\mathrm{R}$ caudate & -0.201 & 0.80 & 0.009 & 0.97 & 0.067 & 0.80 \\
\hline L caudate & -0.162 & 0.80 & -0.108 & 0.90 & -0.028 & 0.95 \\
\hline \multicolumn{7}{|l|}{ BNSS Total } \\
\hline $\mathrm{R}$ medial OFC & 0.462 & 0.07 & -0.374 & 0.20 & -0.281 & 0.22 \\
\hline L medial OFC & 0.051 & 0.95 & -0.365 & 0.20 & -0.021 & 0.95 \\
\hline $\mathrm{R}$ lateral $\mathrm{OFC}$ & 0.083 & 0.95 & -0.624 & 0.009 & 0.005 & 0.97 \\
\hline L lateral OFC & 0.035 & 0.95 & -0.613 & 0.009 & -0.049 & 0.95 \\
\hline
\end{tabular}

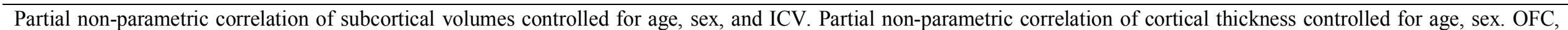
orbitofrontal cortex Bold, significant correlations after FDR correction for multiple comparison (30 tests). 
Structural Correlates of negative symptoms

Table 2B. Group differences of subcortical volumes and OFC thickness

\begin{tabular}{|c|c|c|c|c|c|c|c|c|c|c|}
\hline Region & Group & & & & $\mathrm{df}$ & Error & $\mathrm{F}$ & p-value & Post-hoc & Post-hoc adj $p$ \\
\hline & $\mathrm{HC}$ & SPT & FEP & SZ & & & & & & \\
\hline \multirow[t]{3}{*}{ L caudate } & $3639.70(511.50)$ & $3890.03(557.28)$ & $3690.28(430.25)$ & $3697.61(565.10)$ & 3 & 328 & 4.257 & 0.006 & $\mathrm{HC}<\mathrm{SZ}$ & 0.004 \\
\hline & & & & & & & & & SPT $>$ FEP & 0.045 \\
\hline & & & & & & & & & $\mathrm{FEP}<\mathrm{SZ}$ & 0.003 \\
\hline \multirow[t]{2}{*}{$\mathrm{R}$ caudate } & $3697.50(496.38)$ & $3904.38(497.94)$ & $3736.15(458.28)$ & $3836.90(599.41)$ & 3 & 328 & 3.4513 & 0.017 & $\mathrm{HC}<\mathrm{SZ}$ & 0.001 \\
\hline & & & & & & & & & $\mathrm{FEP}<\mathrm{SZ}$ & $<.001$ \\
\hline \multirow[t]{3}{*}{ L putamen } & $5010.36(512.83)$ & $5142.61(508.93)$ & $5204.66(523.92)$ & $5311.90(689.95)$ & 3 & 328 & 6.334 & $<0.001$ & $\mathrm{HC}<\mathrm{SZ}$ & $<0.001$ \\
\hline & & & & & & & & & $\mathrm{SPT}<\mathrm{SZ}$ & $<0.001$ \\
\hline & & & & & & & & & $\mathrm{FEP}<\mathrm{SZ}$ & $<0.001$ \\
\hline \multirow[t]{3}{*}{ R putamen } & $5073.96(514.93)$ & $5256.83(538.41)$ & $5211.1(550.65)$ & $5301.10(690.46)$ & 3 & 328 & 4.409 & 0.005 & $\mathrm{HC}<\mathrm{SZ}$ & $<0.001$ \\
\hline & & & & & & & & & $\mathrm{SPT}<\mathrm{SZ}$ & 0.026 \\
\hline & & & & & & & & & $\mathrm{FEP}<\mathrm{SZ}$ & $<0.001$ \\
\hline \multirow[t]{3}{*}{ L accumbens } & $479.18(104.86)$ & $512.03(96.27)$ & $485.62(101.02)$ & $568.46(121.05)$ & 3 & 328 & 9.056 & $<0.001$ & $\mathrm{HC}<\mathrm{SZ}$ & $<0.001$ \\
\hline & & & & & & & & & $\mathrm{SPT}<\mathrm{SZ}$ & 0.025 \\
\hline & & & & & & & & & $\mathrm{FEP}<\mathrm{SZ}$ & $<0.001$ \\
\hline $\mathrm{R}$ accumbens & $564.43(95.45)$ & $545.70(86.77)$ & $579.39(80.12)$ & $574.14(111.89)$ & 3 & 328 & 1.7239 & 0.162 & --------- & --------- \\
\hline \multirow[t]{5}{*}{ L lateral OFC } & $2.74(0.12)$ & $2.85(0.17)$ & $2.73(0.13)$ & $2.57(0.15)$ & 3 & 329 & 51.011 & $<0.001$ & $\mathrm{HC}<\mathrm{SPT}$ & $<0.001$ \\
\hline & & & & & & & & & $\mathrm{HC}>\mathrm{SZ}$ & $<0.001$ \\
\hline & & & & & & & & & $\mathrm{SPT}>\mathrm{FEP}$ & $<0.001$ \\
\hline & & & & & & & & & $\mathrm{SPT}>\mathrm{SZ}$ & $<0.001$ \\
\hline & & & & & & & & & $\mathrm{FEP}>\mathrm{SZ}$ & $<0.001$ \\
\hline \multirow[t]{3}{*}{ L medial OFC } & $2.52(0.16)$ & $2.58(0.21)$ & $2.49(0.16)$ & $2.38(0.16)$ & 3 & 329 & 20.516 & $<0.001$ & $\mathrm{HC}<\mathrm{SPT}$ & 0.054 \\
\hline & & & & & & & & & SPT $>$ FEP & 0.018 \\
\hline & & & & & & & & & $\mathrm{SPT}>\mathrm{SZ}$ & 0.002 \\
\hline \multirow[t]{3}{*}{$\mathrm{R}$ lateral OFC } & $2.74(0.16)$ & $2.77(0.18)$ & $2.71(0.17)$ & $2.53(0.13)$ & 3 & 329 & 30.903 & $<0.001$ & $\mathrm{HC}>\mathrm{SZ}$ & $<0.001$ \\
\hline & & & & & & & & & $\mathrm{SPT}>\mathrm{SZ}$ & $<0.001$ \\
\hline & & & & & & & & & $\mathrm{FEP}>\mathrm{SZ}$ & $<0.001$ \\
\hline \multirow[t]{4}{*}{$\mathrm{R}$ medial OFC } & $2.55(0.14)$ & $2.65(0.18)$ & $2.51(0.15)$ & $2.37(0.16)$ & 3 & 329 & 39.369 & $<0.001$ & $\mathrm{HC}<\mathrm{SPT}$ & $<0.001$ \\
\hline & & & & & & & & & $\mathrm{HC}>\mathrm{SZ}$ & 0.010 \\
\hline & & & & & & & & & SPT $>$ FEP & $<0.001$ \\
\hline & & & & & & & & & $\mathrm{SPT}>\mathrm{SZ}$ & $<0.001$ \\
\hline
\end{tabular}

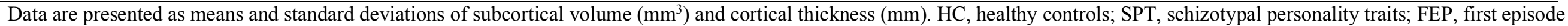
psychosis; SZ, patients with schizophrenia; OFC, orbitofrontal cortex; BF-corrected, Bonferroni correction for multiple comparison. 